\title{
General Psychiatry Oral mucositis induced by risperidone: rare side effect of a frequently prescribed medication
}

To cite: Aguglia A, Amerio A, Proietti L, et al. Oral mucositis induced by risperidone: rare side effect of a frequently prescribed medication. General Psychiatry 2020;33:e100228. doi:10.1136/ gpsych-2020-100228

Received 26 March 2020

Revised 31 May 2020

Accepted 02 July 2020
Check for updates

(C) Author(s) (or their employer(s)) 2020. Re-use permitted under CC BY-NC. No commercial re-use. See rights and permissions. Published by BMJ.

${ }^{1}$ Department of Neuroscience, Rehabilitation, Ophthalmology, Genetics, Maternal and Child Health (DiNOGMI), Section of Psychiatry, University of Genoa, Genoa, Italy

${ }^{2}$ IRCCS Ospedale Policlinico San Martino, Genoa, Italy

${ }^{3}$ Mood Disorders Program, Tufts Medical Center, Boston, MA, USA ${ }^{4}$ Department of Psychiatry, Faculty of Medicine, University of Geneva (UNIGE), Geneva,

Switzerland

${ }^{5}$ Department of Psychiatry, ASO Santi Antonio e Biagio e Cesare Arrigo Hospital, Alessandria, Italy

Correspondence to

Dr Andrea Aguglia;

andrea.aguglia@unige.it

\author{
Andrea Aguglia, ${ }^{1,2}$ Andrea Amerio, ${ }^{1,2,3}$ Luca Proietti, ${ }^{1,2}$ Alessandra Costanza (D) ,, \\ Gianluca Serafini, ${ }^{1,2}$ Mario Amore ${ }^{1,2}$
}

\section{ABSTRACT}

Risperidone is a safe second-generation antipsychotic which is rarely associated with the emergence of a few adverse effects, such as oral lesions and stomatitis. We report the case of a 77-year-old woman affected by a neurocognitive disorder with psychotic features and treated with risperidone $2 \mathrm{mg} /$ day. After 1 week, she showed a burning mouth syndrome with oral lesions and risperidone was discontinued. Antipsychotic-induced oral ulcerations may be caused by the reduction of saliva protection with minor adverse effects related to oral movement disorders or impairment of the bacterial flora of saliva.

\section{INTRODUCTION}

Risperidone is a second-generation antipsychotic which is currently approved and prescribed for a broad range of psychiatric conditions, including schizophrenia, manic episodes in bipolar disorders and short-term treatment of aggressiveness in patients with major cognitive and conduct disorder in the elderly and adolescents, respectively.

Risperidone is a benzisoxazole derivative, and it shows a relevant binding affinity for serotonergic (5- $\mathrm{HT}_{2 \mathrm{~A}}$ and $5-\mathrm{HT}_{7}$ ) and dopaminergic $\left(\mathrm{D}_{2}\right)$ receptors (its affinity for $\mathrm{D}_{3}$ and $\mathrm{D}_{4}$ receptors is three times lower than its affinity for $\mathrm{D}_{2}$ receptors), with a $5 \mathrm{HT}_{2 \mathrm{~A}} /$ $\mathrm{D}_{2}$ affinity ratio of about 20. It also has a higher affinity for adrenergic $\left(\alpha_{1}\right.$ and $\left.\alpha_{2}\right)$ receptors and lower affinity for histaminergic $\left(\mathrm{H}_{1}\right)$ receptors. From a pharmacokinetic point of view, risperidone is rapidly absorbed after oral administration, with peak plasma concentrations approximately 1 hour after administration and an oral bioavailability of $70 \%-85 \%$. It mainly undergoes a 9-hydroxylation in the liver, which produces the active 9-hydroxy-risperidone metabolite (9-OH-RSP) that is mainly catalysed by cytochrome P450 2D6 and, to a lesser extent, cytochrome P450 3A4. ${ }^{1}$

The emergence of oral ulcerations can be associated with different aetiological factors, including trauma, recurrent stomatitis, microbial infections, mucous-cutaneous disease, systemic disorders, squamous cell carcinoma and drug treatment such as atypical antipsychotics.

Although relatively safe and well-tolerated when compared with other first-generation antipsychotics, a number of uncommon adverse effects such as oral lesions could result from the use of risperidone. In addition to the relatively common side effect of dry mouth, a few case reports focused on atypical antipsychotics and their association with oral lesions, such as aphthous stomatitis, pharyngitis, glossitis, oedema and oral ulceration, which may be considered rare clinical complications of risperidone treatment. ${ }^{2-4}$

\section{CASE REPORT}

We report the case of a 77-year-old Italian woman diagnosed with a neurocognitive disorder and admitted to our psychiatric unit for disorganised behaviours, social withdrawal, persecutory delusions and imperative auditory hallucinations. The patient withdrew at home from others, blocking the door with furnishings and hindering entry to her daughter who alerted healthcare staff together with the police. The patient was carried out to the nearby hospital and afterwards underwent psychiatric examination. Finally, she was admitted to our psychiatric unit after a brain scan that ruled out the presence of lesions that could be the basis of psychiatric symptoms. Informed consent was obtained from the patient.

The patient showed no lifetime psychotic symptoms and she had a negative history of perinatal or development abnormalities and/ or general medical diseases. She suffered from recurrent major depressive episodes with mild neurocognitive disorder with psychotic symptoms. A comprehensive physical examination 
and laboratory testing were performed. No specific abnormalities emerged after laboratory tests: her vital signs (blood pressure: 130/85 mm Hg, cardiac rate: sinus rhythm 76 breaths $/ \mathrm{min}$, temperature: $36.6^{\circ}$ ) were stable and no malnutrition was reported. Two evaluation scales were administered: the Brief Psychiatric Rating Scale, with a total score of 65, and Mini-Mental State Examination, with a total score of 21, indicating a mild cognitive impairment. Furthermore, no psychiatric family history was reported.

Haloperidol (2 $\mathrm{mg} /$ day) was prescribed for the first 2 weeks and it was stopped because of extrapyramidal side effects and a partial response. After a wash-out period, the patient's treatment was modified to risperidone, but after 1 week, the patient showed pain and burning mouth syndrome, dysphagia and odynophagia with a consequent $6 \mathrm{~kg}$ weight loss in the following days. Non-steroidal antiinflammatory drugs (administered three times a day) did not control the pain. In addition, she developed oral lesions and white tongue. No clinical improvement was achieved after 1 week of antifungal treatment, and the tongue pain became more severe, occurring even when the patient was not eating. Several diagnostic consultations were requested, such as dermatological, otorhinolaryngological, maxillofacial and dentistry consultations. On the basis of the latter, the most common causes of stomatitis (eg, herpetic viral or other infections, exanthematic diseases, hormonal imbalance, metabolic diseases, vitamin deficiency and pathological alteration of blood cells (ie, leukaemia)), assumption of toxic or irritant substances and cigarette smoke were excluded. Due to the suspicion of a drug-related adverse effect, risperidone was discontinued immediately, despite the clinically significant improvement in psychiatric symptoms.

The mucositis and oral ulcerations were completely solved only after 3 weeks of accurate and adequate oral hygiene (three-five times a day), after which the patient showed a progressive clinical improvement.

\section{DISCUSSION}

In older subjects, several alterations of salivary gland functions can occur, limiting the reserve capacity and leading to increasing vulnerability to side effects: (1) reduction of intensity of salivary reflexes due to the loss of teeth, taste and olfactory receptors; (2) reduction of gland metabolism and size due to the circulating levels of hormones (progesterone, oestrogen and testosterone); and (3) impairment of the blood perfusion of the glands.

Oral health significantly affects many aspects of life, especially in psychiatric patients who often need antipsychotics. Sympathetic and parasympathetic nerves regulated the secretory cells of the parotid and submandibular glands and several drugs that interfere with cholinergic transmission, such as antipsychotics, antidepressants, antiepileptics and sedatives, could attenuate salivary reflexes during their passage through the central nervous system. Recently, Lai and colleagues conducted a population-based retrospective cohort study to compare the incidence of oral ulcerations among antipsychotics users compared with subjects who did not use antipsychotics. The authors showed that the rate of oral ulcerations was highest in the amisulpride group (217.7 per 1000 person-year), followed by quetiapine (193.9 per 1000 person-year), olanzapine (161.9 per 1000 personyear), risperidone (115.6 per 1000 person-year), haloperidol (107.5 per 1000 person-year) and aripiprazole (49.8 per 1000 person-year). Furthermore, the incidence rate of oral ulceration was approximately 15 -fold greater in patients who received antipsychotics compared with those who did not use antipsychotics. ${ }^{3}$

The use of antipsychotics may lead to the emergence of a local trauma and stomatitis of the oral cavity. The onset of oral lesions in patients treated with antipsychotics may be related to (1) extrapyramidal symptoms due to the blockade of dopamine receptors, which may produce involuntary movements of the mouth and tongue, leading to major/minor trauma of the oral cavity; (2) a dry mouth (or xerostomia) that could appear as a result of the blockade of muscarinic receptors with a subsequent reduction in the production of saliva and major predisposition to trauma and ulceration of the oral mucosa as saliva possesses antibacterial properties that prevent infection and may exert a key role in maintaining the equilibrium of saprophytic bacterial flora; and (3) allergic reaction or hypersensitivity side effects of antipsychotic medications, which are rare although patients may develop oral symptoms. ${ }^{56}$

Although there is no clear evidence concerning the aetiological mechanisms underlying antipsychotic-induced oral lesions, this case report supports the hypothesis that antipsychotic-induced oral ulcerations result from the reduction of saliva protection with minor effects related to oral movement disorders or impairment of the bacterial flora of the saliva. Owenby and colleagues ${ }^{7}$ reported an incidence of dry mouth as high as $30.4 \%$ in a review concerning the use of risperidone as augmentation treatment for major depressive disorder. Furthermore, a strong association between antipsychotics and reduction in salivary secretion was found in four 70-year-old Swedish cohorts during a 30 -year period $(n=1072)$ : these findings were adjusted also for gender, cohort and number of teeth. ${ }^{8}$

Importantly, all the agents associated with xerostomia may predispose patients to stomatitis and tongue pain, especially if administered in combination. In order to preclude the development of this complication with such drugs, extra time and efforts should be provided to improve the patient's oral hygiene. As a matter of fact, the management of patients with psychosis primarily involves mechanical debridement, maintenance of proper oral hygiene and removal of potential causative oral agents. In most cases, the elimination of any incriminating factor is usually sufficient to treat the lesions and no drugs are required. Overall, the prognosis of these patients is excellent if the disease is self-limiting. 
In our case, poor oral hygiene due to the psychiatric condition and the use of false dentition may also have predisposed our patient to the onset of stomatitis and mild oral ulcerations leading to the immediate discontinuation of risperidone.

Acknowledgements This work was developed within the framework of the DiNOGMI Department of Excellence of MIUR 2018-2022 (law 232/2016).

Contributors AAg and AAm wrote the first draft of the case report; LP managed the literature searches; $\mathrm{AC}$ reviewed and edited the original draft; GS revised the English language in the manuscript; and MA supervised the search strategy. All the authors contributed to and approved the final version of the manuscript.

Funding The authors have not declared a specific grant for this research from any funding agency in the public, commercial or not-for-profit sectors.

Competing interests None declared.

Patient consent for publication Not required.

Provenance and peer review Not commissioned; externally peer reviewed.

Open access This is an open access article distributed in accordance with the Creative Commons Attribution Non Commercial (CC BY-NC 4.0) license, which permits others to distribute, remix, adapt, build upon this work non-commercially, and license their derivative works on different terms, provided the original work is properly cited, appropriate credit is given, any changes made indicated, and the use is non-commercial. See: http://creativecommons.org/licenses/by-nc/4.0/.
ORCID iD

Alessandra Costanza http://orcid.org/0000-0001-6387-6462

\section{REFERENCES}

1 Leysen JE, Gommeren W, Eens A, et al. Biochemical profile of risperidone, a new antipsychotic. J Pharmacol Exp Ther 1988;247:661-70.

2 Aguglia A, Maina G. Can quetiapine extended release (ER) induce labial edema in a female patient with treatment-resistant major depressive episode? Aging Clin Exp Res 2016;28:791-3.

3 Lai EC-C, Hsieh C-Y, Wong MB, et al. Comparative risk of oral ulcerations among antipsychotics users - population-based retrospective cohort study. Pharmacoepidemiol Drug Saf 2016:25:123-32.

4 Gürbüz HGA, Seçinti DD, Neze H. Clozapine-Induced late-onset angioedema. Indian J Psychiatry 2020;62:95-6.

5 Zolotukhin S. Metabolic hormones in saliva: origins and functions. Oral Dis 2013;19:219-29.

6 Kuppili PP, Nebhinani N, Jain S, et al. Olanzapine associated palpebral edema: an uncommon adverse effect of a commonly prescribed drug. Asian J Psychiatr 2018;36:60-1.

7 Owenby RK, Brown LT, Brown JN. Use of risperidone as augmentation treatment for major depressive disorder. Ann Pharmacother 2011;45:95-100.

8 Johanson CN, Österberg T, Lernfelt B, et al. Salivary secretion and drug treatment in four 70-year-old Swedish cohorts during a period of 30 years. Gerodontology 2015;32:202-10.

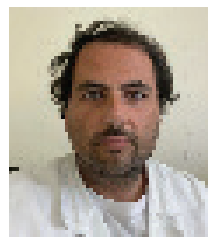

Andrea Aguglia graduated with honors in Medicine and Surgery from the University of Trieste in Italy in 2008, and achieved the specialization in Psychiatry at the University of Turin in Italy in 2014. He completed his PhD in Neuroscience at the University of Turin in Italy in 2019. Now he is working as a researcher in Psychiatry at the Department of Neuroscience, Rehabilitation, Ophthalmology, Genetics, Maternal and Child Health, University of Genoa, Section of Psychiatry, IRCCS Ospedale Policlinico San Martino, Genoa, Italy. He participates in several clinical trials and has given presentations at national congresses (organized by the Italian Society of Psychopathology, Italian Society of Psychiatry, and Italian Society of Neuropsychopharmacology). His main research interests include major depression (mechanisms and treatment of resistant depression), bipolar disorder (clinical features and impact of environmental/meteorological variables on the illness course), obsessive-compulsive disorder (comorbid condition and differentiation of $O C D$ from $O C D /$ tic) and suicide (characteristics associated with the lethality of suicide attempts, the method used, and single vs. multiple attempters and cognitive / biological aspects of suicide). 